Archivum, LXX (II), 2020, pp. 27-58

\title{
¿Evidencialidad como posible herramienta de manipulación? \\ La evidencialidad quechua en algunas traducciones de textos religiosos
}

\author{
ENRIQUe BERnÁRdez SANChÍs \\ Universidad Complutense de Madrid \\ ebernard@filol.ucm.es
}

Recibido: 17/05/2020

Aceptado: 24/09/2020

\section{RESUMEN:}

En estas páginas analizamos la evidencialidad quechua en algunos textos religiosos evangélicos contemporáneos, para comprobar si su funcionamiento es el habitual o muestra discrepancias achacables a alguna forma de manipulación. Estas traducciones al quechua muestran un funcionamiento de la evidencialidad distinto al habitual: o total carencia de marcadores, o sobreutilización del marcador de evidencialidad directa sin representación de ningún otro. Para ubicar estos textos en el contexto global de la lengua quechua, la primera parte es un repaso del sistema evidencial quechua, así como un breve análisis de su funcionamiento en textos escritos antiguos (siglos XVI y XVII), junto con textos narrativos del siglo XX, incluyendo textos orales. La segunda parte presenta el análisis de los textos religiosos contemporáneos.

PALABRAS CLAVE: evidencialidad; manipulación lingüística; quechua 


\title{
Evidentiality as a posible tool for manipulation? Quechua evidentials in some translations of religious texts
}

\begin{abstract}
:
The Quechua evidentiality system is analyzed in some contemporary Christian religious texts, to check whether their functioning is the usual one or shows any discrepancies attributable to some form of manipulation. The Quechua translations show a functioning of evidentiality different from what could be expected: complete absence of evidential markers or overabundence of the direct evidence marker in absence of any other. In order to clearly place them within the global picture of Quechua evidentiality, the first part of the paper is devoted to a review of the Quechua evidential system and a brief analysis of its functioning in ancient written texts (16th and 17th centuries), as well as a few 20th c. narrative texts, including oral narratives. The second part is an analysis of the contemporary religious texts.
\end{abstract}

KEY WORDS: evidentiality, linguistic manipulation; Quechua.

\section{Introducción}

Algunas versiones contemporáneas de textos religiosos en lengua quechua muestran un carácter atípico en la utilización de marcadores evidenciales, como el de evidencialidad directa -mi y el reportativo -si. Los textos que consideramos aquí son la traducción de la Biblia al quechua ayacuchano por un grupo bíblico norteamericano evangélico, y la versión parcial del Libro de Mormón al quechua cuzqueño, por la Iglesia de los Santos de los Últimos Días. En ambos casos se trata de versiones que cuentan con la aprobación de los credos correspondientes. Este artículo indaga en el tema para confirmar o rechazar la hipótesis de que el anómalo uso de la evidencialidad en estas traducciones puede considerarse una forma de manipulación lingüística. Para ello se hace necesario considerar el comportamiento de los evidenciales -mi/-si/-sqa- en diversas variedades quechuas y a lo largo de la historia conocida del idioma. Asimismo, que se busca presentar el texto, considerado sagrado y como herramienta de evangelización, como plenamente fiable, lo que se vería contradicho de 
usarse el reportativo, habitual en los relatos quechuas, de modo que se utiliza solo el evidencial directo o ninguno en absoluto.

\section{Evidencialidad: definición y definiciones}

Como definición estándar de evidencialidad podemos tomar la de Alexandra Aikhenvald:

Evidentiality proper is understood as stating the existence of a source of evidence for some information; this includes stating that there is some evidence, and also specifying what type of evidence there is. Evidentiality systems differ in how complex they are (Aikhenvald 2003: 1)

Sin embargo, en la nutrida bibliografía sobre evidencialidad se realizan muchas matizaciones y variaciones, sobre todo a partir del doble desplazamiento radical que representa (1) la reinterpretación de lo que inicialmente se definió como un fenómeno gramatical, morfológico o morfosintáctico, a una categoría conceptual universal que, además, no necesitaba ser obligatoria; $y$, consecuentemente, (2) el traslado del centro de investigación, desde las lenguas para las que se definió originalmente el término, a todas las del mundo y, por consiguiente, muy mayoritariamente, hacia algunas que carecen de evidencialidad 'gramatical' y disponen solo de mecanismos léxicos para su expresión. En estas páginas no podemos entrar en una discusión del complejo ámbito de estudio de la evidencialidad en sus distintos aspectos, tema sobre el que existe una abundantísima bibliografía internacional -y también en castellano.

Como el quechua es una lengua con evidencialidad morfológica de uso habitual, aunque no estrictamente obligatorio, nos atendremos a la definición inicial y a los estudios en este ámbito, y no a los dedicados a lenguas con otros tipos de evidencialidad.

\subsection{Evidencialidad en quechua}

El quechua dispone de varios marcadores de evidencialidad; aquí nos fijaremos en los siguientes: el marcador de evidenciali- 
dad directa $-m(i)$ y el de evidencialidad secundaria, o reportativo, -s(i), teniendo en cuenta también el 'pretérito narrativo' -sqa-. En esta primera parte revisamos brevemente los valores asignados habitualmente a los marcadores; asimismo, tenemos en cuenta algunas interpretaciones que completan las habituales.

El lingüista peruano W. Hurtado de Mendoza Santander ve la evidencialidad como inserta en la expresión deíctica: "La función deíctica de los evidenciales es la de marcar la modalidad de la experiencia del hablante sobre la que construye la red de significaciones y sentidos que constituyen el mensaje" (Hurtado de Mendoza, 2002: 136). Pone además de relieve el papel de la "certidumbre con la que el hablante asume el contenido del mensaje" (p. 137). Así, el evidencial directo quechua -mi "se caracteriza por insertar la presencia del hablante como punto de referencia y por destacar el contexto del mensaje como una consecuencia directa de su percepción" (136). Esta forma de ver la evidencialidad como una forma de deíxis tiene raíces antiguas, aunque haya desaparecido de la discusión actual sobre el tema, como observa Manley (2015: 145):

While Jakobson (1957), building on Jespersen (1923), was the first to classify evidentials as a type of deictic 'shifter', anchoring utterances to the context of speech and shifting reference, depending on the context, the vast majority of the cross-linguistic literature fails to recognize the status of evidential, epistemic and mirative markers as markers of stance or of deixis.

Si ampliamos la perspectiva a otras lenguas no emparentadas pero provistas también de evidencialidad gramatical, vemos que parecida es para Mahieu (2016: 156) la función del valor del marcador no directo -viniq en kalaallisut, pues "il exprime ... que le référent de ce nom [al cual va afijado] n'appartient pas en tant que tel à son champ d'expérience possible, ni au moment (...) dont parle l'énoncé, ni à un moment ultérieur". Ahn y Yap (2015) tienen también un planteamiento semejante para el coreano. Pa- 
recida es asimismo la opinión de Faller para el quechua (2002); más allá de la función de señalar la fuente de información de que ha dispuesto el hablante,

the meaning of the so-called Direct evidential -mi of Cuzco Quechua in assertions, and of simple assertions without an evidential $[\ldots]$ conveys that the speaker has the best possible grounds for making the assertion, but (...) only -mi encodes this meaning; sentences without an evidential implicate it (121).

Por ello,

(...) a speaker who uses -mi claims to have authority over the information conveyed. This second aspect of authority also extends to personal information: a person who witnessed an event has more authority over that piece of information than a person who did not (p.135).

Como vemos, no se trata solo de una marca de fuente de información, ni siquiera de la adopción por el hablante de la responsabilidad sobre el contenido que transmite, sino también de autoridad del hablante sobre su mensaje.

En cuanto a la función del reportativo -s(i), Hurtado de Mendoza (2002: 145) la define así:

El hablante marca con -s el hecho de que los contenidos de su mensaje no son consecuencia de su experiencia directa sino que le han sido reportados, por tanto, el hablante solo infiere y transmite la información que, de hecho, proviene de una fuente distinta a él mismo como hablante.

Parece que el reportativo tiene esa función específica, y hemos de asumir que es el opuesto del evidencial directo, de modo que marca la falta de autoridad del hablante sobre su propio mensaje. De ahí que -mi, además de que se trata de algo perci- 
bido directamente por el hablante, marque también el grado de confiabilidad o certeza de lo dicho (p. 141): solo quien ha observado $\mathrm{X}$ puede afirmar X con total garantía, es decir, fiabilidad, autoridad y certeza.

Hemos de añadir que, al menos en las variedades meridionales, el evidencial $-m(i)$, pero también en ciertas condiciones el reportativo $-s(i)$, pueden servir para marcar foco y tópico (cfr. Muntendam, 2015).

En cuanto al llamado 'pretérito narrativo' ${ }^{1}$, con marca -sqa(frente al pretérito usual, -rqa-), Hurtado de Mendoza (2002: 91), siguiendo a Cerrón Palomino, indica que se usa

para indicar una acción ejecutada en el pasado sin control por parte del hablante [...] (Con ella,) el hablante no asume responsabilidad de la acción de la que da cuenta [...]. (Sirve para dar cuenta) de los hechos históricos, legendarios y míticos y de aquellos realizados en estados de inconsciencia.

\subsubsection{Lo cultural y discursivo en la evidencialidad}

Nos parece interesante la observación de Faller de que, en ausencia de evidencial, pues los marcadores no son obligatorios en quechua, se infiere que el contenido del mensaje es percibido directamente como fiable, etcétera. Podemos añadir que es imprescindible estudiar los evidenciales, más allá de su función en oraciones aisladas, en su contexto comunicativo y cultural, es decir, como insertados en el discurso y, en consecuencia, en contextos y situaciones socioculturales. Sabemos, por ejemplo, que ciertas categorías socioculturales priman sobre la posible 'objetividad' del conocimiento directo o indirecto. Así, Aikhenvald (2003: 23) señala que "[t]he choice of evidentials may correlate with cultural stereotypes and with attitudes to knowledge. In Tariana and in Shipibo-Konibo, shamans use visual evidentials to relate their knowledge and supernatural experiences: these are viewed as

1 Incluye la expresión de la categoría denominada miratividad, pues indica acciones, etc., inesperadas o que producen sorpresa. 
real". Un relato chamánico de lo observado en 'el otro mundo' es cierto porque estamos convencidos de que el chamán realmente estuvo allí y vio lo que dice que vio (Valenzuela, 2003: 51); lo que, evidentemente, solo es válido para los miembros del grupo cultural del chamán. En términos que nos serán útiles más abajo, para quienes creen en la realidad de la experiencia del chamán. ¿Tal vez esté aquí la motivación para los usos de evidenciales en los textos religiosos que estudiamos? ¿Han de entenderse como equivalentes a relatos chamánicos?

La importancia solo relativa de la existencia de una fuente concreta puede deberse, en términos aún más generales, al papel social del hablante (en general pero, sobre todo, en el discurso). Como señala Mahieu (2016: 174), “Dans une langue de culture orale, la parole individuelle constitue par défaut un acte d'engagement de la part du locuteur. Les marques d'évidentialité indirecte y jouent donc le rôle inverse des signatures que nous apposons sur les documents écrits". Esto es, el hablante puede ir señalando constantemente que no se implica en la veracidad de lo relatado. Bernárdez (2017) incide en cómo la presencia de un reportativo suele ir acompañada de la mención explícita de la fuente concreta de conocimiento, pues su función central no es poner de relieve la existencia de una fuente externa, sin más, sino que el hablante no se implica en la veracidad de su relato. Por su parte, Floyd (2005) destaca la importancia de la evidencialidad gramatical desde el punto de vista poético y rítmico; es decir, para construir la narración tradicional.

Adelaar (1997: 12) pone de relieve que "[e]l uso de los marcadores de validación y evidencialidad trae consigo opciones más o menos flexibles o adaptables según el contexto, el género del texto y las intenciones del locutor". En algunos textos, la función narrativa de los evidenciales parece incluso más importante que su función evidencial propiamente dicha; así, en un texto que probablemente refleja un mito precristiano, llama la atención 
la alternancia de -si y - mi en un relato de acontecimientos que el narrador no pudo haber presenciado personalmente. Las oraciones que forman parte del hilo principal del relato van acompañadas por el marcador de información no-directa -si. Por otro lado, las partes explicativas y las supuestas consecuencias, igualmente míticas, de lo narrado vienen con -mi (p. 11)

Podemos resumir señalando que: el evidencial directo quechua (1) indica la no necesidad de una fuente externa al hablante y, normalmente, que ella no existe. (2) Señala que el hablante acepta la responsabilidad de sus palabras. (3) Da a entender que lo narrado es cierto, sea por haber sido presenciado por el hablante, sea porque así se acepta en virtud de su posición en el grupo. (4) Confirma que hablante y oyente(s) se encuentran en un mismo ámbito de experiencia. (5) Otorga preminencia al elemento al que se sufija (tópico/tema/foco). Por su parte, el indirecto o reportativo (1) indica, en principio, que lo narrado no es conocido de primera mano por el hablante, sino probablemente por otra persona o fuente. (2) Señala que el hablante no se considera responsable de la veracidad de lo narrado. (3) No indica directamente nada sobre la veracidad o no de lo narrado. (4) Apunta a que hablante y oyente no comparten el mismo ámbito de experiencia. (5) Puede otorgar preminencia al elemento al que se afija.

Finalmente, el uso de ambas formas de evidencialidad depende de factores discursivos y textuales, como la función de los segmentos de texto en que aparecen. También podríamos decir que esos distintos valores de la evidencialidad quechua (y de otras lenguas, probablemente) son resultado de factores discursivos, textuales y culturales. Y más aún, que la función de los marcadores de evidencialidad puede ser más cuestión de organización textual que de mero significado independiente.

Naturalmente, habremos de tener en cuenta la complejidad funcional de la evidencialidad para poder validar o rechazar nuestra hipótesis de trabajo: no puede juzgarse solamente a partir de la presencia o ausencia de evidenciales, sino de sus funcio- 
nes dentro del texto, sean estas de carácter propiamente evidencial, o de algún otro tipo, como ha quedado de manifiesto en las páginas anteriores.

\subsection{Una nota histórico-dialectal sobre la evidencialidad quechua}

Para comprobar si la ausencia total o el uso aparentemente desviado de los evidenciales en las traducciones contemporáneos que nos interesan corresponde a algún tipo de uso de los mismos en otras épocas o variedades del quechua, es necesario hacer un breve repaso de ambos aspectos. Porque existiría la posibilidad de que las traducciones religiosas actuales utilizaran una forma de lengua de resonancias antiguas, como sucede con las versiones tradicionales al inglés de los textos bíblicos, o con el Libro de Mormón (que sigue ese mismo estilo, el de la traducción denominada King Jame's version, publicada inicialmente en 1611). Es necesario puntualizar que las traducciones que analizaremos son protestantes o evangélicas, no católicas, pues ha sido imposible localizar o consultar traducciones católicas integrales; además, las traducciones protestantes tienen su origen en grupos misioneros de EEUU.

\subsubsection{Variación dialectal}

El sistema evidencial es básicamente idéntico en todas las variedades de quechua, aunque en alguna el sistema parece complicarse, como sucede en la de Yauyos (Shimelman, 2017, sección 6.2.11: Evidence, y Apéndice B). En esta variedad quechua se usan los mismos marcadores $-m(i)$ y $-s h(i)$ con los valores habituales, pero el sistema se amplía con otros evidenciales que no consideramos en estas páginas. Sobre el quichua ecuatoriano, Floyd (2005) pone de relieve que no se usa el sufijo habitual sino la partícula verbal nin, 'dice', que no existe en otros dialectos. Para el quechua ecuatoriano de Imbabura, Gómez Rendón (s.f., 11) señala que esta partícula está siendo sustituida por el castellano dizin; además, al parecer, el evidencial directo -mi está con- 
virtiéndose en un focalizador y perdiendo función evidencial (p. 22), lo que implicaría una reorganización total del sistema de evidencialidad. Por otra parte, el reportativo -shi ha pasado a tener función de evidencial inferencial (Gómez Rendón 2006: 38). Las variedades del kichua septentrional, incluido el inga colombiano, muestran también la reorganización completa del sistema. Señalemos que la lengua quechua llegó hasta allí como última fase del desplazamiento del imperio inca y que seguramente sufrió la influencia de las lenguas habladas en la zona, aunque es probable que hubiera un periodo en que se utilizó allí alguna variedad de quechua como lengua comercial, antes de la llegada de la administración imperial (Etxebarria, 2018: 245), lo que pudo conducir al desarrollo de una variedad 'mixta', influida por las lenguas regionales.

En las demás variedades que hemos consultado, la presencia y las funciones de -mi y -shi son básicamente coincidentes, desde los dialectos meridionales: Santiago del Estero (Nardi, 2002), Cochabamba (Solá y Lastra, 1976), Cuzco (Faller, 2002, 2003), a los peruanos centrales: Chanca (Zariquiey y Córdova, 2008), Ayacucho-Chanca (Soto Ruiz, s.f.), Cajamarca (Rimashun kichwapi, 2006) y Wanka (Cerrón Palomino, 2018). Aunque, naturalmente, la revisión no ha sido ni mucho menos exhaustiva, todo parece indicar que, con la excepción de (la mayoría de) las variedades de quichua septentrional (Ecuador, Colombia), las demás muestran considerable uniformidad en la forma y la función de los evidenciales -mi y -shi.

\subsubsection{Antigüedad del sistema}

El sistema evidencial es, sin duda, antiguo, como se puede colegir por (1) la escasa diferenciación dialectal, (2) la imposibilidad de analizar los sufijos (es decir, las fuentes de una probable gramaticalización no resultan accesibles) y (3) su existencia ya en tiempos de la conquista. Las primeras gramáticas escritas por misioneros españoles comentan tanto las condiciones formales de uso como las funciones de estos evidenciales. 
Así, en la de González Holguín: "S. fobre dicciones, que fe acaban en vocal, fi fobre las que en confonante o dos vocales, firven dizen que, como ñcas cayfi, payfi, dicen que yo, o tu, o aquel" (p. 32). Diego de Torres (1619: 31 v.) hace referencia, además, a los equivalentes castellanos: "S. fi (...) poftpuefta a verbos, o nombres fignifica aquel común romãce dizen que, o diz que"2.

Sobre el uso y la función de $-m(i)$ no se suele decir mucho, aunque González Holguín especifica en detalle a qué palabras puede acompañar, de acuerdo con las características del verbo. Pero indica que "firven en las oraciones de indicativo" (p. 31). La apelación al indicativo parece interesante como referencia al modo realis, frente el irrealis del subjuntivo.

\subsubsection{Textos quechuas de los primeros tiempos}

Como vemos, pues, desde los primeros que describieron el quechua se reconoció el uso de estos elementos, que ahora llamamos evidenciales, y se contrastó con el uso castellano. De modo que en los primeros textos quechuas podemos esperar usos semejantes a los descritos en las variedades recientes. Así sucede si nos fijamos en un largo texto de carácter narrativo como es el Manuscrito de Huarochirí, pero también, aunque en mucha menor medida, en algunos otros de los primeros años; disponemos de cartas y peticiones en quechua, desde finales del siglo XVI, de personas agraviadas que piden la compensación de los ultrajes sufridos. Estas peticiones incluyen breves descripciones o relatos de lo sucedido, en los que encontramos con relativa frecuencia el sufijo - $m i$, más como énfasis o focalización que en función de evidencialidad. Por ejemplo, en los escritos de carácter judicial privado recogidos por Durston

2 En la lengua actual se mantiene la distribución: - m/-s detrás de vocal, -mi/-si detrás de consonante. El sufijo es siempre el último elemento de la palabra, y esta puede ser sustantivo, adjetivo, adverbio, verbo, demostrativo, conector... Por su parte, -sqa- aparece detrás de la base verbal, delante de sufijos personales y otros morfemas; no tiene forma abreviada pero es homófona con la marca de participio pasado, que cumple funciones adjetivales o nominales y va seguido de los morfemas nominales correspondientes. 
(2003) y datados a partir de 1587 hasta entrado el siglo XVII, no aparecen apenas marcadores evidenciales, aunque hay casos de - $m(i)$, como en maymantam apamusac, "¿de dónde- $\mathrm{M}^{3}$ los traeré?" (p. 227); llicllamanta quinssa varcotam mañacuni "por una liclla pido tres pesos-M (p. 228)"; algún escrito cuenta con varios ejemplos de -mi: cusaymi testamentota ruracuspam vañorcan "mi-marido-MI hizo-M testamento antes de morir", almanpac entieronpac saquicurcanmi cacnitacama "para el alma y para el entierro dejó-MI (dinero) para pagar (misas)" (p. 230) y así sucesivamente en toda la parte inicial de la carta, en la que se van exponiendo los hechos, a los que el evidencial aporta mayor fuerza.

En otros escritos, - $m i$ aparece en la parte final, como refuerzo de la petición de resarcimiento. Algo parecido encontramos en las "nueve peticiones (un total de veinte páginas) presentadas en 1679 como parte de una demanda contra el cura de Chuschi por los pueblos de Chuschi, Choque Huarcaya, Auquilla y Tomanga" (Durston y Urioste, 2013: 379).

Itier (1991) publica varias cartas redactadas en 1616, en las que hallamos la misma situación que en las recogidas por Durston: uso relativamente frecuente de -mi y ausencia de -si, lo que parece lógico habida cuenta de que lo escrito (cartas de tipo personal) cuenta necesariamente con el reconocimiento, por su autor, de la propia responsabilidad sobre el texto, que se presenta como realmente sucedido.

\subsubsection{Otros textos tradicionales}

Sin entrar en cuestiones de antigüedad, que son muchas veces irresolubles (cfr. Durston, 2010, sobre los himnos cusqueños), podemos mencionar algunos textos de carácter anónimo o, al menos popular. En himnos cristianos como los de Cuzco que publica Pilco Paz (2014) encontramos un uso ocasional del evidencial -mi, más como refuerzo de la responsabilidad del hablante que con

3 Indicaré el evidencial quechua en el texto en cursiva, y en la versión española, con M/MI o S/SI unidas con guion a la palabra a la que están sufijadas. 
valor evidencial propiamente dicho; un par de ejemplos: Qanmi Dios kanki; Mana qanwanqa / wañuykuymanmi. / Mana chaywanqa / usuykuymanmi (Tú-MI eres Dios; Sin ti / yo perecería-MI / Sin eso (el pan de los ángeles) / yo estaría perdido-MI (p. 25). Paymi chaskin manunchista / paymi pichan huchanchista (él-MI (Cristo) acepta la deuda / él-MI limpia el pecado) (p. 27). Lo mismo sucede en los himnos citados por Durston (2010). Baste con un ejemplo (p. 151):

$\begin{array}{ll}\text { Yarccallahuanmi, } & \text { Tengo hambre-MI } \\ \text { Ucuyquimanta, } & \text { de tu cuerpo, } \\ \text { chaqquillahuanmi, } & \text { tengo sed-MI } \\ \text { unuyquimanta } & \text { de tu agua. }\end{array}$

En cuentos de narración oral, la situación es más compleja. Veamos uno recogido por Margit Gutmann (2005) y que se supone que recoge un antiguo mito. Jacinto Q., el narrador, comienza con la ubicación legendaria de los sucesos: Kay llaqtanchismantas, kay llaqtamanta kasqaku karan machukuna antes, antesraq "De-este nuestro-pueblo-S de-este pueblo había-(SQA) todavía viejos antes, mucho antes ${ }^{4}=$ Hace tiempo-S, hace mucho tiempo existían todavía los viejos de nuestro pueblo, de este pueblo." (p. 263-264); como vemos, utiliza el reportativo para desligarse del relato, tanto -s como el pretérito en -sqa-. En el resto del cuento se repite el reportativo en nuevas secciones, iniciadas por hinaspas, 'y entonces-S', que aparece sin evidencial, hinaspa, en el interior de una sección. A falta de un estudio más detallado, parece que el reportativo, además de su función como evidencial indirecto, se usa para dividir el relato en secciones. Un punto de especial importancia en el relato mítico, la captura de la serpiente, se expresa también con reportativo: sirpitaqa hap'irqonsi ‘la serpiente(+acusativo+tematizador) agarró-SI'. Es de destacar que no existen ejemplos del evidencial -mi. Por otra parte, se usa constantemente la forma verbal de pretérito relacionada con la

4 Añado esta traducción literal propia, para mostrar más exactamente la estructura; va seguida de la que proporciona la autora del artículo. 
evidencialidad, marcada con el sufijo -sqa-, frente al más neutro y habitual -rqa-. Por ejemplo, ka-sqa-ku 'existían' de la primera línea. De modo que podemos decir que este relato está plenamente marcado como desligado de la responsabilidad del narrador, que lo presenta como algo 'que se cuenta'.

En un cuento titulado De la apuesta entre el cóndor y el zorro, recogido por la misma autora (Gutmann 2007), y que no posee carácter mitológico, el narrador, Don Jacinto, no usa evidenciales, pero sí, con exclusividad, el pasado en -sqa-. Podemos decir que la carencia de evidenciales apunta a que se siente 'dueño del relato', como suele suceder con los cuenteros; pero evita el compromiso directo de los pasados en -rqa-, dando a su narración un carácter alejado de la realidad cotidiana. El pretérito en -sqa- que caracteriza el relato, alterna con formas de presente que sirven para introducir secciones, en una forma de presente histórico.

El mismo cuadro aparece en la versión en quechua de Kaunas del cuento El gallo y el zorro (Arguedas, 2018). Conectores con el reportativo, como haypiši ${ }^{5}$ 'entonces', hayĉuuši 'y entonces/ después-SI', alternando con formas sin evidencial para marcar transiciones menores, como, hayĉu 'allí, entonces', y evidencial directo para elementos descriptivos en un entorno ya marcado como narrativo/reportativo, p.ej.- hayĉumi mikayalkan 'allí-MI estaban comiendo'. El principio del texto lo marca ya como algo que cae fuera de la responsabilidad del hablante: Unay unayñă 'hace mucho, mucho ya [ña]-SI'. No es preciso hacer un análisis más exhaustivo del cuento, pero vale la pena señalar que en la parte final encontramos la intervención del narrador que comenta el cuento y lo da por concluido. Y entonces utiliza el evidencial directo de responsabilidad - $m i$. El contenido del texto 'no pertenece' al narrador, pero sí su comentario final.

Lo cierto es que estos textos de carácter oral y tradicional muestran un uso de la evidencialidad que encaja bien con lo ex-

5 Mantengo la ortografía de Arguedas, que recoge peculiaridades dialectales de Kaunas, como las consonante /š/ (por/s/ de otros dialectos) y la grafía $<\hat{c}>$ en vez de la normalizada $<\mathrm{ch}>$. 
puesto al principio de este artículo: el uso no es automático ni depende solo de la existencia o no de una fuente externa o la percepción directa por el narrador, sino que incluye elementos de focalización, organización textual y, quizá sobre todo, hace referencia al grado de 'propiedad del narrador' sobre su relato. Si no lo es, como en el cuento mítico, se utiliza el reportativo asociado al pretérito que podemos denominar también reportativo; si lo es plenamente, como en el cuento popular no mítico, el carácter 'irreal' de lo narrado queda solamente en manos del verbo en reportativo.

\subsubsection{El manuscrito de Huarochirí}

Este texto, escrito seguramente a instancias del misionero Francisco de Ávila, pero por un quechua hablante nativo, narra mitos paganos -que el misionero deseaba combatir, para lo cual necesitaba conocerlos. La fecha de redacción no está clara, pero es ciertamente anterior a 1606 (pese a Taylor, 1986, que habla de 1607). Como no tenemos espacio para un análisis ni siquiera superficial de este extenso texto, nos detendremos solo en un par de puntos importantes. Existen tres ediciones principales, que son las que aquí tendremos en cuenta: Trimborn (1939), que incluye el texto quechua y una versión alemana, Taylor (2008), bilingüe quechua-español, y la también bilingüe de Arguedas (2011) .

Como el texto es muy variado, el comportamiento de los evidenciales no es uniforme. Por ejemplo, el comienzo del capítulo 7 no desarrolla un mito antiguo sino una festividad que se seguía celebrando en el momento de la escritura. Eso hace que tengamos un elevado número de evidenciales directos y que, en cambio, el de reportativos sea pequeño. El motivo es, seguramente, que lo que se cuenta ha sido visto y vivido por el narrador. El uso de los reportativos indica que lo que sigue se hunde en una antigüedad legendaria; por ejemplo:

6 Estas son las que utilizo. Existen ediciones anteriores de Arguedas y Taylor, y una posterior de Trimborn. 
Chaymi ña chayta muchašpari pichqa punçhawši chay kišwarwan qinçhašpa runakunaktapaš mana purichišpa chaypi tiyapayarqan. Chayši ña chayta puchukašpa rarqa pichaynintawanpaš tukuyta ña puchukašpaš chaymanta takišpa runakuna hamurqan.

[entonces-MI] Hacían una cerca de quishuar alrededor de su santuario y permanecían allí cinco días-SI durante los cuales no permitían que la gente saliera a pasear. [Entonces-SI] Se dice que, cumplido este rito, proseguían con la limpieza de la acequia y, cuando habían terminado todo, regresaban bailando.

De modo que este breve capítulo separa claramente dos niveles mediante los evidenciales: el de los sucesos contemporáneos, accesibles directamente al narrador $\mathrm{y}$, posiblemente, también al oyente/lector, y aquellos ya no practicados porque se trataba de ritos, ceremonias o fiestas paganas. El traductor lo marca claramente: 'Se dice que...'

En el capítulo 16 se retoma un tema tratado en un capítulo anterior (el $8^{\circ}$ ). Cuando el autor se refiere a lo contado en ese capítulo, usa el evidencial directo. En cambio, pasa al reportativo cuando la referencia es al mito en sí (el nacimiento, de cinco huevos, de los hermanos o hijos de Pariacaca).

Cuando el texto relata algo mítico, el reportativo es ubicuo; véase por ejemplo el principio del capítulo 2:

Kay Quniraya Wiraquchaš ancha ñawpa huk runa ancha wakcha tukušpalla purirqan yaqullanpaš kušmanpaš lliki llikisapa. Runakunapaš ${ }^{7}$ wakin mana riqsiqninkunaqa 'wakcha usasapa' ñišpaš qayarqan. Kay runaš kanan tukuy llaqtakunakta kamarqan. Çhakraktapaš rimašpallaš pata-pataktapaš allin pirqašqakta tukuchirqan. Rarqaktaš kanan lluqšimunanmanta huk "pupuna"

7 -paš es un sufijo usado para marcar enumeraciones; no está formado con el reportativo, aunque puede aparecer un homófono -pa-s cuando el evidencial se sufija a un sustantivo en genitivo. 
šutiyuq kañaweralpa sisayninwan chuqašpallaš yaçhakuchirqan. Chaymantari ima haykaktapaš rurašpaš purirqan, wakinnin llaqta wakakunaktapaš yaçhašqanwan allquchašpa.

Chayši huk mitaqa huk warmi wakataq Qawillaqa šutiyuq karqan. Kay Qawillaqaš kanan wiñay donsella karqan. Panaš ancha sumaq kaptin, pi mayqan waka willkakunapaš "puñušaq" ñišpa munapayarqan. Chayši manataq huñirqanchu. Chaymantaš kanan qipanpi chay warmiqa chay hina mana pi qaritapaš çhankaykuchikušpa, huk yura rukmap sikinpi awakurqan. Chayši chay Quniraya amawta kayninpi huk pišqu tukušpa chay yura rukmaman wichay rirqan. Chayši chaypi huk rukma çhayašqa kaptin, chayman yumayninta çhurašpa urmachimurqan chay warmi qayllaman. Chayši chay warmiqa ancha kušikušpa millpuykurqan. Chayši hinalla çhiçhu tukurqan mana qarip çhayašqan. Isqun killapi, imanam warmikunapaš waçhakun, hina waçhamurqan, hina donsellataq. Chayši kikillantaq huk wata chika ñuñunwan kawsachirqan, "Pip churinçhá kayqa?" ñišpa.

En la traducción de Taylor (añado conectores entre corchetes):

Dicen que, en tiempos muy antiguos, Cuniraya Huiracocha-S, tomando la apariencia de un hombre muy pobre, se paseaba con su capa y su cusma hechas harapos. Sin reconocerlo, algunos hombres lo trataban de mendigo piojoso. Ahora bien, este hombre-S transmitía la fuerza vital a todas las comunidades. Con su sola palabra-S preparaba el terreno-S para las chacras y consolidaba los andenes $\mathrm{y}$, con tan sólo arrojar-S una flor de un cañaveral llamado pupuna, abría una acequia-S desde su fuente. Así, realizando toda clase de hazañas, andaba humillando a los demás huacas locales con su saber.

[Entonces-SI] Había una vez una mujer llamada Cahuillaca que también era huaca. Esta Cahuillaca-S era todavía doncella. [Entonces-SI] Como era muy hermosa-S, todos los huacas y huillcas deseaban acostarse con ella. Pero ella siempre los rechazaba. [Des- 
pués-S] Sucedió que esta mujer, que nunca se había dejado tocar por un hombre, estaba tejiendo debajo de un lúcumo. [Entonces-S] Cunitaya, gracias a su astucia, se convirtió en pájaro y subió al árbol. [Entonces-S] Como había allí una lúcuma madura, introdujo su semen en ella y la hizo caer cerca de la mujer. [Entonces-S] Ella, sin vacilar, muy contenta, se la comió. Así quedó preñada sin que ningún hombre hubiera llegado hasta ella. Nueve meses más tarde, como-M suele suceder con las mujeres, Cahuillaca también dio a luz, pese a ser todavía doncella. [Entonces] Durante más o menos un año, crio sola a su hijo, amamantándolo. Siempre se preguntaba de quién podría ser hijo.

La última frase aparece en el original en estilo directo, y así la traduce Arguedas: “' ¿Hija de quién será?' se preguntaba”. También Trimborn utiliza el estilo indirecto.

Trimborn utiliza, para traducir el reportativo, una de las formas habituales de expresión del mismo en alemán, con el verbo sollen: soll Cuniraya W.; und doch soll er es gewesen sein; soll es nun auch einen weiblichen Huak'a gegeben haben; und so soll sie schwanger geworden sein. Arguedas, por su parte, renuncia a la expresión del evidencial en castellano.

Como podemos ver en el texto, el reportativo aparece constantemente, con sustantivos y verbos, de modo que todo el relato se marca claramente como historia oída, no conocida directamente. Sucede en todo el manuscrito. Mucho más infrecuente es el marcador de evidencialidad directa: lo que ha sido observado o es objeto de conocimiento directo.

\subsubsection{Uso de los evidenciales por los primeros traductores} misioneros

Los misioneros conocedores del quechua eran conscientes de la función de estos sufijos. Dedenbach-Salazar Sáenz $(2018,189)$, al analizar el uso de las formas verbales en la traducción castellano-quechua de uno de los confesionarios conservados, señala que la frase ymácta ruraspam cocurcanqui, traducción del castella- 
no "y como las offresciste?" (el complemento es: las cosas que se dan a los seres sobrenaturales) ofrece la acción "como presenciada (-m de evidencia)". La autora ofrece la siguiente versión literal de la frase quechua: “¿Haciendo qué -te he visto [no lo niegues]- [les] diste a tu manera?".

Por otra parte, como indica Durston $(2007,306)$, la lengua utilizada por los misioneros era, para usar términos actuales, la "normativa", que debía servir para usos pastorales: "Pastoral Quechua was no missionary pidgin... The texts they provide made full use of Quechua's unique and gramatical resources $(\ldots)^{\prime \prime}$, aunque nunca se pretendió convertirla en un instrumento propio de las personas a las que iba dirigida (p. 307).

\subsubsection{Textos escritos contemporáneos}

Podemos comprobar si lo dicho hasta aquí se mantiene en textos contemporáneos escritos, es decir, que no representan directamente la oralidad. José María Arguedas, escritor peruano cuya primera lengua fue el quechua, usa la evidencialidad de una forma reconocible en sus relatos, aunque también en su poesía. Por ejemplo, en el relato breve titulado Ararankaymanta (El lagarto) (Arguedas, 1986, 96), encontramos este inicio: Huk apu runas kasqa 'había-SQA un hombre-S rico', con el reportativo sufijado al sustantivo runa 'hombre' y el verbo en forma narrativa/ reportativa: kasqa (había, era). Un comienzo semejante es el del famoso relato Pongoq mosqoynin (El sueño del pongo): huk runas pongo turnunman risqa 'un hombre-S fue-SQA a su turno de pongo $^{\prime 8}$ (en Arguedas, 2009, 127); el uso simultáneo del reportativo -s y del verbo narrativo risqa nos presenta un texto del que su autor, diríamos, se separa para transmitirlo como algo ajeno, lo que en el segundo relato se pone de relieve con la indicación de que es un 'cuento quechua'. En El lagarto, se establece una separación del relato en partes mediante hinaptinsi, con el reportativo, que es

8 El pongo era una prestación obligatoria, de carácter temporal, de los aparceros de un terrateniente. Siguiendo turno, tenían que acudir a su domicilio para encargarse de las labores que el señor (wiraqocha) deseara asignarles. 
equivalente al hinaspas que vimos más arriba. A lo largo de todo el texto seguimos encontrando conectores semejantes sufijados con -s(i) y verbos en pretérito reportativo -sqa- que van marcando todo el texto como 'ajeno' al escritor. En El sueño del pongo las cosas son algo distintas porque es en gran parte un diálogo. Pero aparece, por ejemplo, wakchan-mi 'es pobre-MI' con el evidencial directo y en la función de refuerzo que ya conocemos.

En otro momento del El lagarto, cuando el matrimonio ha tenido un niño con forma de lagarto, se produce un breve diálogo. La madre insiste en que, como el lagarto es realmente su hijo, tienen que buscarle esposa:

‘Wawanchikmi, churinchikmi, imaynapas casarachisunyá. Casarichisun" nispa, iskaynin tayta maman rimanakuspa riki yaykupanku sipasman. Chaysi yachanku, riki ararankay churin kasqantaqa.

Es nuestro hijo-MI. Tendremos que hacerlo casar, de algún modo. Ha de tener mujer", dijeron los padres. [Entonces-S]Y fueron a pedir una muchacha para él.

'Es nuestro hijo-MI, es nuestra criatura-MI' ${ }^{9}$ son afirmaciones de la madre que indican su pleno convencimiento, de ahí que estén marcadas con el evidencial directo; en cambio, el marcador chaysi vuelve al relato propiamente dicho, y se marca con el reportativo. Como vemos, el funcionamiento es muy semejante al de Huarochiri y otros textos antiguos.

Sucede hasta en los poemas quechuas del mismo Arguedas, donde - $m i$ aparece para reforzar como autoritativa la afirmación del autor -aunque no se trate de una verdad "objetiva", sino solo poética o metafórica; última estrofa del poema Carnaval taki / Canción de carnaval:

9 Arguedas, en su versión castellana, reduce esta construcción, típica del quechua tradicional y de los textos orales, sobre todo los poéticos. 
Munankichu yachaykuyta maymantachus kani chayta, Jhak'aychimpa huertamantam rosas waytapa chaupinmantam clavelinaspa chaupinmantam. ¿quieres saber

de dónde soy?

Mira esa huerta-M en la ladera: entre rosas de un jardín-M en un jardín-M de clavelinas. ${ }^{10}$

\subsection{Conclusiones de la sección 2}

Las funciones conocidas de los evidenciales aparecen en textos de todo tipo y distinta época, orales y escritos. Si tenemos en cuenta los tipos de texto y las funciones de cada parte de un texto, así como el papel (sociocultural) del autor, hallamos una coincidencia clara con lo definido en los estudios lingüísticos sobre la evidencialidad quechua. No existen diferencias significativas ni entre los textos más antiguos y los contemporáneos, ni entre unos dialectos quechuas y otros. Hemos de tener en cuenta todo esto, a la hora de juzgar las traducciones que veremos a continuación para confirmar o no nuestra hipótesis de partida. Vale la pena señalar que los textos bíblicos incluyen numerosos tipos de texto (poéticos, narrativos, etc.), que corresponden a los que hemos repasado en esta sección.

\section{Traducciones de textos religiosos al quechua}

\subsection{El Libro de Mormón}

Hemos revisado varios fragmentos de la versión parcial del Libro de Mormón a quechua cuzqueño (2016) buscando ejemplos de -mi, -si y la forma verbal -sqa- como pretérito, es decir, no como participio en función de adjetivo o sustantivo. Los fragmentos analizados han sido los siguientes:

Libro 1 de Neftí, capítulo 1, v. 1-24; cap. 6; cap 17, v. 1-12; Libro 2 de Neftí, 1: 1-12; Libro de Enós, vv. 20-25; Libro de Mosiah, cap. 2, v. 10-12; Libro de Alma, cap. 5, vv. 1-2; Libro 3 de Nefti,

10 Esta versión es más cercana al original; Arguedas hace su propia autotraducción: Qué tanto me preguntas / de dónde vengo, de dónde soy. / Mira esa huerta en la ladera; / allí he nacido, / entre rosas y clavelinas / y entre flores he vivido. 
cap. 12, v. 1-5 y cap. 15, v. 1-5; Libro de Mormón, cap. 1, v. 7-15 y cap. 8: 32-36.

El total acumulado de ocurrencias de cada uno de los tres marcadores es el siguiente:

$\begin{array}{ll}-m i & 0 \\ -s i & 0 \\ -s q a- & 0\end{array}$

Como vemos, no existen marcadores evidenciales, en una ausencia que no se puede considerar casual ni ligada a tipos de texto (los fragmentos incluyen discursos y relatos). Aparte de representar un quechua un tanto anómalo, a tenor de lo visto en las páginas anteriores, la traducción 'esquiva' cualquier referencia evidencial. Podríamos decir que el texto, y lo que narra, está libre de todo asomo de duda, que se presenta como realidad indiscutible garantizada por un narrador de absoluta fiabilidad, conocimiento y responsabilidad sobre su texto. Está, diríamos, 'más allá de toda evaluación humana'. Esto no se nos indica de manera explícita sino que se produce mediante inferencia (como indica Faller 2002, cf. más arriba, 2.1.1.): es el lector mismo -o el oyente- el que infiere la autoridad plena e indiscutible del narrador y de su texto. Basarse en inferencias es una forma de manipulación de lenguaje muy frecuente, como han señalado Domaneschi y Penco (2016). Podríamos añadir que es una manipulación especialmente insidiosa, porque en el texto no hay nada explícito que encamine al receptor en esa senda interpretativa.

Naturalmente, las cosas se pueden interpretar de otras formas: al otorgarse carácter sagrado a un texto, este sería inmutable e indudable, lo que 'justificaría' extirpar cualquier posible duda al respecto. Para esa forma de verlo es imprescindible, evidentemente, la fe en la sacralidad del texto. Aunque es posible que la manipulación lingüística vaya dirigida, precisamente, a conseguir que el receptor se convenza y crea firme y ciegamente 
en la veracidad y sacralidad del libro. También podríamos pensar que la ausencia de marcadores es consecuencia de un inadecuado conocimiento de la lengua; lo que, sin embargo, no parece posible habida cuenta de que los marcadores evidenciales están entre los primeros elementos que se aprenden en quechua, la frecuencia de su uso y la complejidad del texto traducido, que pone de manifiesto un perfecto dominio de la lengua $y$, muy probablemente, la participación directa de hablantes quechuas cuzqueños en la traducción, como es habitual en este tipo de trabajos desde hace decenios.

\subsection{La traducción de la Biblia}

Analizamos a continuación la traducción evangélica del texto bíblico al quechua ayacuchano, publicada por la evangélica Sociedad Bíblica Peruana, afiliada a la organización estadounidense Wycliffe Bible Translators. Debido a la longitud del texto (que sí aparece en su integridad en esta versión, tanto el Antiguo como el Nuevo Testamento) nos limitaremos a una colección de fragmentos. Veremos en primer lugar el Nuevo Testamento.

\subsubsection{Nuevo Testamento}

Del este hemos analizado los siguientes fragmentos:

Mateo: 1:18-24; 2: 1-12; 8: 1-13; 27: 32-44.

Marcos: $1: 1-13 ; 6: 45-51 ; 11: 1-11 ; 15: 1-12$.

Lucas: $1: 26-38 ; 8: 4-8 ; 15: 11-32$.

Juan 1: 1-5; 20: 11-18.

Hechos 3: 1-10; 5: 17-23; 7: 54-60; 9: 1-9.

Apocalipsis: 1: 4-8; 3: 1-6; 4: 1-10; 7: 1-10; 11: 1-10; 15; 22: 1-5.

No hemos hallado ni un solo caso de -si; uno solo de -sqaverbal, y 177 de $-m(i)$. La frecuencia de este evidencial directo parece muy anómala: aproximadamente 1,86 ocurrencias por versículo en los fragmentos estudiados, muy superior a la de 
cualquier texto de cualquier otra clase. El análisis incluye fragmentos de todo tipo, narrativos y no narrativos; hemos hecho una comprobación en dos parábolas, puramente narrativas y con un contenido literal que no parecería necesario considerar exactamente 'sagrado': la del Hijo pródigo (Lucas 15: 11-32), que muestra un promedio de 1,95 -m(i) por versículo, y la del Sembrador (Lucas 8:4-8), con 1,2 de promedio. Parece curioso que en los fragmentos del Apocalipsis la abundancia del evidencial directo es mayor aún que en los Evangelios (1,5 por versículo), pues se eleva a 2,46 ocurrencias por versículo, aunque es aún mayor en Hechos $(2,86)$. Podríamos pensar: ¿quizá porque el contenido del Apocalipsis es más 'extraño', más difícil de creer, y por ello se pone más de relieve la veracidad por medio del evidencial? ¿Tal vez porque Hechos narra las acciones de los apóstoles, que conducen directamente a la actividad misionera plasmada en estas traducción?

Lo que dijimos más arriba sobre el Libro de Mormón puede repetirse aquí, aunque con una salvedad importante: si allí se echaba mano de la inferencia del receptor, aquí se insiste explícitamente una vez tras otra, machaconamente, podríamos decir, en la fiabilidad y veracidad del texto, su realidad y su autoridad. No es raro encontrar en una misma oración dos o incluso más ocurrencias de $-m(i)$ : en el sujeto o el objeto, el verbo y un conector. Los conectores, por cierto, cuya función en unión al reportativo hemos visto en páginas anteriores, aparecen con frecuencia pero no marcados o, más frecuentemente aún, con el evidencial directo.

\subsubsection{Antiguo Testamento}

El Antiguo Testamento no difiere de lo que hemos visto en el Nuevo. Los fragmentos estudiados han sido:

Génesis 1, 2, 6 (v. 9-22), 7, 11 (v. 1-8);

Salmos 1;

Cantares 1;

Eclesiastés 8 (v. 1-6). 
El promedio de evidenciales directos por versículo es de 1,91, semejante al de los fragmentos del Nuevo Testamento. Los números para cada fragmento, en el orden indicado, son: 1,$54 ; 1,84$; 1,$78 ; 1,30 ; 2,62 ; 1,83 ; 2,05 ; 2,33$.

Aparte de la magnitud de las cifras, llama la atención que el carácter narrativo o no de los textos parece carecer de importancia. Entre los fragmentos estudiados se encuentran los que narran la creación del mundo y el hombre, la construcción del arca de Noé y el diluvio, la construcción de la torre de Babel, claramente narrativos, pero también textos poéticos como un salmo y uno de los Cantares atribuidos a Salomón.

El azar no puede tener mucho papel en esta curiosa situación: cero casos de reportativos, sea -s(i) o el verbal -sqa-, y un número elevadísimo de evidenciales directos. La consecuencia es que el texto se presenta explícita y reiteradamente como cierto, indiscutido, dependiente de la autoridad absoluta del productor (¿que quizá se supone es Dios?). Podríamos decir que una parte de la estructura de la lengua quechua se ha retorcido para proporcionar un mensaje de absoluta fiabilidad. Estos usos no existen en ningún dialecto quechua ni en textos conocidos desde los tiempos de la conquista y la colonia.

Veamos un ejemplo del texto ayacuchano, donde resaltamos las ocurrencias del evidencial directo.

Hechos 22: 6-11: 6 -Damasco llaqtaman chayaykuchkaptiyñam yaqa chawpi punchawta cielomanta qonqayta llumpay achkiy anchaykuwarqa. 7 Chaymi pampaman wichiykuspay uyarirqani "Saulo, Saulo ¿imanasqataq qatikachawanki?" niqta. 8 Chaymi tapurqani: “¿Pitaq kanki Señor?” nispa. Hinaptinmi nimuwarqa: "Ñoqaqa qatikachawasqayki Nazaretmanta kaq Jesusmi kani" nispa. 9 Riqmasiykunapas rikurqam chay achkiytaqa ichaqa manam entienderqakuchu chay imapayawaqniypa nisqantaqa. 10 Hinaptinmi tapurqani: “¿Imatataq rurasaq Señor?” nispa. Payñataqmi niwarqa: "Hatarispayki Damasco llaqtaman yaykuy, chaypim imam ruranaykita nisunki" nispa. 11 Chay sinchi achkiy ñawsayarachi- 
waptinmi riqmasiykuna makiymanta pusawaspanku Damasco llaqtaman chayachiwarqaku.

\section{Una traducción literal:}

6. Llegando-ya-M cerca de-la-ciudad-de Damasco a-mitad-del día, desde cielo de-repente enorme luz me-rodeó. 7. EntoncesMI al-suelo cayéndome oí “Saulo, Saulo, ¿por-qué me-persigues? -diciendo. 8 Entonces-MI pregunté: “¿Quién eres, Señor?” dije. Y-entonces-MI me-dijo: "Yo en-verdad de-Nazaret siendo, Jesús-MI soy» diciendo. 9. También-mis-compañeros vieron-M aquella luz entonces no-M entendían aquello ciertamente afirmaron. 10. Enconsecuencia-MI pregunté: “¿Y-qué haré, Señor?” diciendo. Y-él-MI me-dijo: "Te-levantarás a-Damasco ciudad ve, allí-M qué-M harás te-dirán" diciendo. 11. Aquella fuerte luz habiéndome-cegado-MI compañeros de-la-mano llevándome a-Damasco ciudad llegué. ${ }^{11}$

Como se puede comprobar, todos los puntos del texto están marcados como indudables: (1) luz al acercarse a Damasco; (2) palabras de Jesús; (3) pregunta de Saulo y respuesta de Jesús, que 'se presenta'; (4) los compañeros de Saulo ven la luz; (5) nueva pregunta de Saulo, y respuesta de 'él', que indica dónde sucederá qué; (6) ceguera y viaje a Damasco. Esto es: todo lo que se quiere transmitir al receptor está marcado con este evidencial. Los pretéritos, además, no dejan lugar a dudas: todos están marcados con el sufijo-rqa-. Destacaremos, finalmente, que los sucesivas partes

11 En la versión revisada de Casiodoro de Reyna: “6 Mas aconteció que yendo yo, y llegando cerca de Damasco, como a mediodía, de repente me rodeó mucha luz del cielo; 7 y caí al suelo, y oí una voz que me decía: Saulo, Saulo, ¿por qué me persigues? 8 Yo entonces respondí: ¿Quién eres, Señor? Y me dijo: Yo Soy Jesús de Nazaret, a quien tú persigues. $9 \mathrm{Y}$ los que estaban conmigo vieron a la verdad la luz, y se espantaron; mas no oyeron la voz del que hablaba conmigo. 10 Y dije: ¿Qué haré, Señor? Y el Señor me dijo: Levántate, y ve a Damasco, y allí te será dicho todo lo que te está señalado hacer. 11 Y como yo no veía a causa de la claridad de la luz, llevado de la mano por los que estaban conmigo, vine a Damasco." (Las Sagradas Escrituras. Traducida por Casiodoro de Reina (1569)... cotejada con la revisión de Cipriano de Valera (1602). Bogotá: Colombia para Cristo, 1996). 
del episodio están marcadas con conectores: Chaymi (introduce sección 2); Chaymi (intr. sección 3); Hinaptinmi, que introduce el resto del texto, la parte que puede considerarse esencial, y que lo muestra como una consecuencia de lo anterior: 'por tanto', en una estructura textual INTRO-SECCIÓN 1-SECCIÓN 2-RESULTADO de 1-2. Todos estos conectores están señalados con - $m(i)$. Y todo parecido con la organización de los textos quechuas vernáculos 'parece mera coincidencia', podríamos concluir.

Por lo demás, el lenguaje utilizado en la traducción de la Biblia responde al quechua coloquial, con un gran número de préstamos castellanos; se supone que así es plenamente accesible a cualquier conocedor del quechua ayacuchano -o de la mayoría de las variedades quechuas, en realidad, sobre todo las más meridionales, como cuzqueño, boliviano o santiagueño. También en la versión del Libro de Mormón encontramos una lengua de estas características, aunque tal vez un tanto más formal, con menos préstamos del español.

\section{Conclusiones}

El resultado de este estudio parece confirmar la hipótesis: en las versiones analizadas encontramos una lengua anómala en lo tocante al uso o ausencia de marcadores evidenciales. Esta forma de lengua no parece haber existido nunca, ni en ningún dialecto de la lengua quechua. En lo relativo a la traducción bíblica hemos consultado fragmentos de traducciones a otras variantes, pero los resultados son esencialmente los mismos que hemos identificado para la versión ayacuchana, de modo que no nos pareció necesario entrar en detalles que serían pura reiteración de lo visto. Parece evidente que se trata, en el caso de las versiones de la Biblia por esta organización religiosa, de una estrategia traductológica consciente y aplicada de forma concienzuda. Estas versiones pueden consultarse en la página web https: //www.bible.com.

La situación del Libro de Mormón, con su total falta de marcadores, es especialmente extraña, pues el texto queda, podríamos decir, 'mutilado', pues el lector u oyente no puede hacer- 
se opinión propia alguna sobre lo narrado y ha de limitarse a aceptarlo sin matices (¿se trata de eso precisamente? ¿Es esa la intención de los traductores?). La extrañeza de la traducción bíblica es de otra clase: todo, absolutamente todo, se presenta explícitamente como verdadero, autoritativo, fiable... En el Libro de Mormón, por buscar otras diferencias, la veracidad del texto se deja en manos del receptor, que debe inferirla. En la Biblia, en cambio, el receptor es dirigido constante y concienzudamente en esa misma dirección. ¿Obedece esto a diferencias en las formas de actividad misionera? Es cuestión que no podemos abordar aquí.

Habría sido conveniente consultar biblias u otros textos religiosos de otras iglesias, como la católica, lo que no ha sido posible, como se indica más arriba. Por eso, las presentes conclusiones solamente son válidas para los textos evangélico y mormón que han sido objeto de análisis.

\section{Referencias bibliográficas}

A) Traducciones que utilizamos

EL LIBRO DE MORMÓN. MORMOMPA LIBRONMANTA. Traducción (parcial), de 1991. Iglesia de los Santos..., Utah, EEUU.

LA BIBLIA EN QUECHUA AYACUCHANO. Segunda edición digital, Lima, Sociedad Bíblica Peruana, 2011.

B) Bibliografía utilizada

AdelaAr, Willem F. H. (1997) “Los marcadores de validación y evidencialidad en quechua: ¿automatismo o elemento expresivo?", Amerindia 22, 3-13.

Ahn, M., y H.F. YAP (2015). "Evidentiality in interaction", A pragmatic analysis of Korean hearsay evidential markers, Studies in Language, 39(1), 46-84.

Aikhenvald, Alexandra (2003) “Evidentiality in typological perspective", en Aikhenvald, A. and RMW Dixon (eds.). Studies in evidentiality. Amsterdam, John Benjamins, 1-33. 
Arguedas, José María (1986) Cantos y Cuentos Quechuas, Lima, Municipalidad de Lima Metropolitana.

Arguedas, José María (2009) Qepa Wiñaq. Siempre. Literatura y antropología. Prólogo de Sibyla de Arguedas. Ed. crítica de Dora Salas, Madrid y Frankfurt a.M., Iberoamericana/Vervuert.

Arguedas, José María (2011) MANUSCRITO DE HUAROCHIRÍ. LIBRO SAGRADO DE LOS ANDES PERUANOS. Versión bilingüe ... de José María Arguedas. Edición y estudio al cuidado de José Ignacio Úzquiza González, Madrid, Biblioteca Nueva.

Bernárdez, Enrique (2017) “Evidentiality-A Cultural Interpretation", en Farzad Sharifian (ed.), Advances in Cultural Linguistics. Singapore, Walter de Gruyter, 433-459.

Cerrón Palomino, Rodolfo (2018) Wanka Quechua, IJAL, 84, Supp. 1, 157-164. DOI 10.1086/695551.

Dedenbach-Salazar Sáenz, Sabine (2018) ““ ¿Sueles decir al hechicero: 'Adivina para mí'?" - Funcionalidad gramatical en las traducciones al quechua de cinco confesionarios coloniales", Indiana, vol. 35 (2), 175-207.

Domaneschi, Filippo y Carlo Penco (2016) Come non detto. Usi e abusi dei sottintesi, Roma, Laterza.

Durston, Alan (2003) “La escritura del quechua por indígenas en el siglo XVII. Nuevas evidencias en el Archivo Arzobispal de Lima (estudio preliminar y edición de textos)", Revista Andina, 37, 207-236.

Durston, Alan (2007). Pastoral Quechua. The history of Christian translation in colonial Peru, 1550-1650, Notre Dame (US), U. of Notre Dame Press.

Durston, Alan (2010) “Apuntes para una historia de los himnos quechuas del Cusco", Chungara, Revista de Antropologia Chilena 42(1), 147-155.

Durston, Alan y George Urioste (2013) “Las peticiones en quechua del curato de Chuschi (1678-1679)", en Marco Curatola Petrocchi y José Carlos de la Fuente Luna (eds.), El quipu colonial: Estudios y materiales, Lima, P.U. C. del Perú, 379-440. 
Etxebarria, Maitena (2018). "Bilingüismo y realidad sociolingüística de la lengua inga en Colombia", ASJU 52(1/2), 237-251. http://www.ehu.es/ojs/index.php/ASJU/ (consultado 5/5/2020). DOI: https://doi.org/10.1387/asju.20201.

Faller, Martine T. (2002) Semantics and Pragmatics of Evidentials in Cuzco Quechua, PhD Thesis, Stanford University.

Faller, Martina (2003) "Propositional- and illocutionary-level evidentiality in Cuzco Quechua", en Jan Anderssen, Paula Menéndez-Benito and Adam Werle (eds.), The Proceedings of SULA 2, Amherst, University of Massachusetts, 19-33.

Floyd, Simeon (2005) "The Poetics of Evidentiality in South American Storytelling", en L. Harper, \& C. Jany (eds.), Proceedings from the Eighth Workshop on American Indigenous languages, Santa Barbara (US), University of California, Santa Barbara. (Santa Barbara Papers in Linguistics; 46), 28-41.

Gómez Rendón, Jorge (s.f.) Imbabura Quechua (Ecuador). En la página personal del autor en Universiteit van Amsterdam, www. uva.nl > personalpages > tab-two > tab-two > asset

Gómez Rendón, Jorge (2006) "Interpersonal aspects of evidentiality in Ecuadorian Quechua", ACLC Working Papers 1, 3750 .

GonzÁlez Holguín, Diego (1614) ARTE, Y VOCABVLARIO EN LA LENGUA GENERAL DEL PERV, llamada Quichua, y en la lengva Efpañola, Lima, Imprenta de Francisco del Campo, (la primera edición se publicó en 1586).

Gutmann, Margit (2005) “El mito del Qanchi Machu: Creación del espacio sagrado y sus repercusiones en la historia regional cusqueña (Perú)", Revista Andina, 40, 261-277.

Gutmann, Margit (2007) “Diseños culturales en cuentos orales quechuas", Revista Andina, 44, 249-262.

Hurtado de Mendoza S., William (2002) Pragmática de la cultura y la lengua quechua, Quito, Abya-Yala.

Itier, César (1991) "Lengua general y comunicación escrita: Cinco cartas en quechua de Cotahuasi-1616", Revista Andina, 17, p. 65-107. 
Jakobson, Roman (1957) Shifters, verbal categories and the Russian verb. Cambridge (US), MIT Press.

Jespersen, Оtтo (1923) Language: Its Nature, Development and Origin, London, George Allen and Unwin.

Mahieu, Marc-Antoine (2016) “Les marqueurs d'évidentialité indirecte en inuktitut: expérience vécue ou pas?", Amerindia 38, 145-176.

Manley, Marilyn S. (2015) "Multidimensional Markers of Evidential, Epistemic and Mirative Stance in Cuzco Quechua", en Manley y Muntendam (eds.), 145-207.

Manley, Marilyn S. y Antje Muntendam (eds., 2015) Quechua expressions of stance and deixis, Leiden, Brill.

Muntendam, Antje (2015) "Discourse Deixis in Southern Quechua: A Case Study on Topic and Focus", en Manley y Muntendam (eds.), 208-258.

Nardi, Ricarlo L. J. (2002) Introducción al quichua santiagueño, Leila I. Albarracín, Mari C. Tebes y Jorge R. Alderetes, compiladores. San Miguel de Tucumán (Argentina), Editorial Dunken.

Pilco Paz, Enrique (2014) Himnos religiosos en quechua. Música tradicional de la región Cusco, Cusco, Dirección Desconcentrada de Cultura de Cusco.

Rimashun Kichwapi. HABLEMOS EN QUECHUA. Una introducción al quechua cajamarquino (2006), Lima, S.I.L.

Shimelman, Aviva (2017) A grammar of Yauyos Quechua (Studies in Diversity Linguistics 9), Berlin, Language Science Press.

Solá, Donald F. y Yolanda Lastra (1964) The structure of Cochabamba Quechua. U.S. Dept. of Health, Education \& Welfare. Office of Education.

Sото Ruiz, Clodoaldo (s.f.) RUNASIMI-KASTILLANU-INLIS LLAMKAYMANAQ QULLQA. Ayakuchu-Chanka, Lima, CSRPARWA.

Taylor, Gerald (1985) “Un documento quechua de Huarochiri -1607", Revista Andina 3(1), 157-185. 
Taylor, Gerald (ed., 2008) Ritos y tradiciones del Huarochirí, Edición bilingüe etc. Lima, Instituto Francés de Estudios Andinos e Instituto de Estudios Peruanos.

Torres Rubio, Diego de (1609) Arte, Confeffonario, y Vocabulario de la lengua Quichua. Lima.

Trimborn, Hermann (1939) Francisco de Ávila. Dämonen und Zauber im Inkareich. Trad. e introd. de H. T. Leipzig, F. K. Koehler Verlag.

Valenzuela, Pilar M. (2003) “Evidentiality in Shipibo-Konibo, with a comparative overview of the category in Panoan", en Aikhenvald y Dixon (eds. 2003), 33-62.

Zariquiey, Robert y Gavinia Córdova (2008) QAYNA, KUNAN, PAQARIN. Una introducción práctica al quechua chanca, San Miguel, P.U.C. del Perú. 